\title{
Urban Water Balance 1. A Model for Daily Totals
}

\author{
C. S. B. Grimmond, T. R. OKe, AND D. G. SteYN
}

Department of Geography, The University of British Columbia, Vancouver, British Columbia, Canada

\begin{abstract}
The water balance provides a framework through which to study the interactions between the elements of the hydrologic cycle. This paper presents a simple model for evaluating the components of the urban water balance based on standard climate data and easily obtained parameters to describe the site. The time scale can be varied from 1 day to at least 1 year depending on the availability of appropriate input data and the form of the evapotranspiration submodel chosen. The evapotranspiration model proposed is of the combination type with modifications to allow for application to the suburban environment. An important methodological concept throughout the model is the recognition that a suburban area can be subdivided into three discrete surface types for hydroclimate purposes (impervious, pervious unirrigated, and pervious irrigated). Presented in this paper is an outline of the model, sensitivity analyses, and information for its implementation.
\end{abstract}

\section{INTRODUCTION}

Water supply and flood runoff have been dominant research foci of urban hydrology, largely because of their direct importance in water resource and storm water management considerations [Hengeveld and De Vocht, 1982]. In much of this work it is either stated, or implicit, that other hydrologic processes are of negligible importance. The present study takes a broader view of the urban water system by explicitly invoking the concept of a water balance. The use of the water balance (which is the principle of mass conservation applied to exchanges of water) ensures that the magnitudes of the various water exchange processes are viewed in context. In addition, this approach allows investigation of the interaction between the elements of the hydrologic cycle.

This paper, the first of two, presents a model for evaluating the components of the urban water balance based on standard climate data and easily obtained parameters to describe the site. The second paper [Grimmond and Oke, this issue] reports the result of a study using this model in a suburban area of Vancouver, British Columbia, for 1 year.

Such a model could be used in conjunction with existing urban runoff models to provide a "continuous" simulation, i.e., a running water balance for a catchment between storms. This would be of great value in determining the water status of the surface prior to the next precipitation event. The present model permits a more rigorous determination of the evapotranspiration than is usually employed in continuous simulation models. More traditional continuous simulation models have utilized evaporation pan data: see, for example, the Wenzel and Voorhees [1980] adaptation of the Illinois Urban Drainage Area Simulator (ILLUDAS) model and the Alley et al. [1980] parametric-deterministic model. The model could also be used to study water conservation strategies. Knowledge of water use patterns together with evapotranspiration and the other components of the water balance give insight into where water is lost from the system and where control measures may be most effective. The model has already been useful in identifying the role of urban irrigation in the urban

Copyright 1986 by the American Geophysical Union.

Paper number 5W4317.

0043-1397/86/005W-4317\$05.00 energy budget and therefore in urban climate [Grimmond and oke, this issue].

\section{URBan HYDROLOGIC SYSTEM}

The water balance of an urban volume, which can be considered to be a box with unit surface horizontal area that extends from roof level to a depth in the ground below which no net exchange of water occurs over the period of interest [Oke, 1978, Figure 8.7b], may be expressed on an areal basis as a depth of water:

$$
p+I=r+E+\Delta S
$$

where $p$ is precipitation, $I$ is the piped-in water supply, $r$ is net runoff, $E$ is evapotranspiration, and $\Delta S$ is the net water storage change.

The urban system (Figure 1) differs from that of undeveloped areas in that in addition to the standard hydrologic cycle, there is the provision of piped water supply and organized water disposal (gutters, sewers, floodways, and snow removal). This gives rise to two urban water subsystems. First, the "internal" system, which consists of water piped into, and out of, the buildings for drinking, sanitary, industrial, and cooling purposes (i.e., it does not interact with the outdoor environment within the catchment). Second, the "external" system consists of all the remaining water exchanges in the catchment including piped water applied for irrigation, swimming pools etc.

In some urban areas where water use is restricted to genuinely internal domestic or industrial purposes the external cycle is almost unaffected; thus the two cycles are isolated, and two distinct balances exist. These lend themselves to simple accounting methods, especially if sanitary and storm sewers are separate, and supply pipe leakage is small. More commonly, very significant amounts of water are released to the external environment for example via irrigation, vaporization in industrial cooling, pipe leakage, outfall into streams, and the internal and external systems are thereby coupled.

In the suburban case, to be considered here, the systems can be effectively decoupled in the following ways: (1) on the input side of equation (1) the portion of piped water supply (I) attributable to internal water use throughout the year can be approximately equated to the mean daily water use in winter [American Water Works Association, Committee on Water Use (AWWA-CWU), 1973]; similarly, (2) on the output side, 


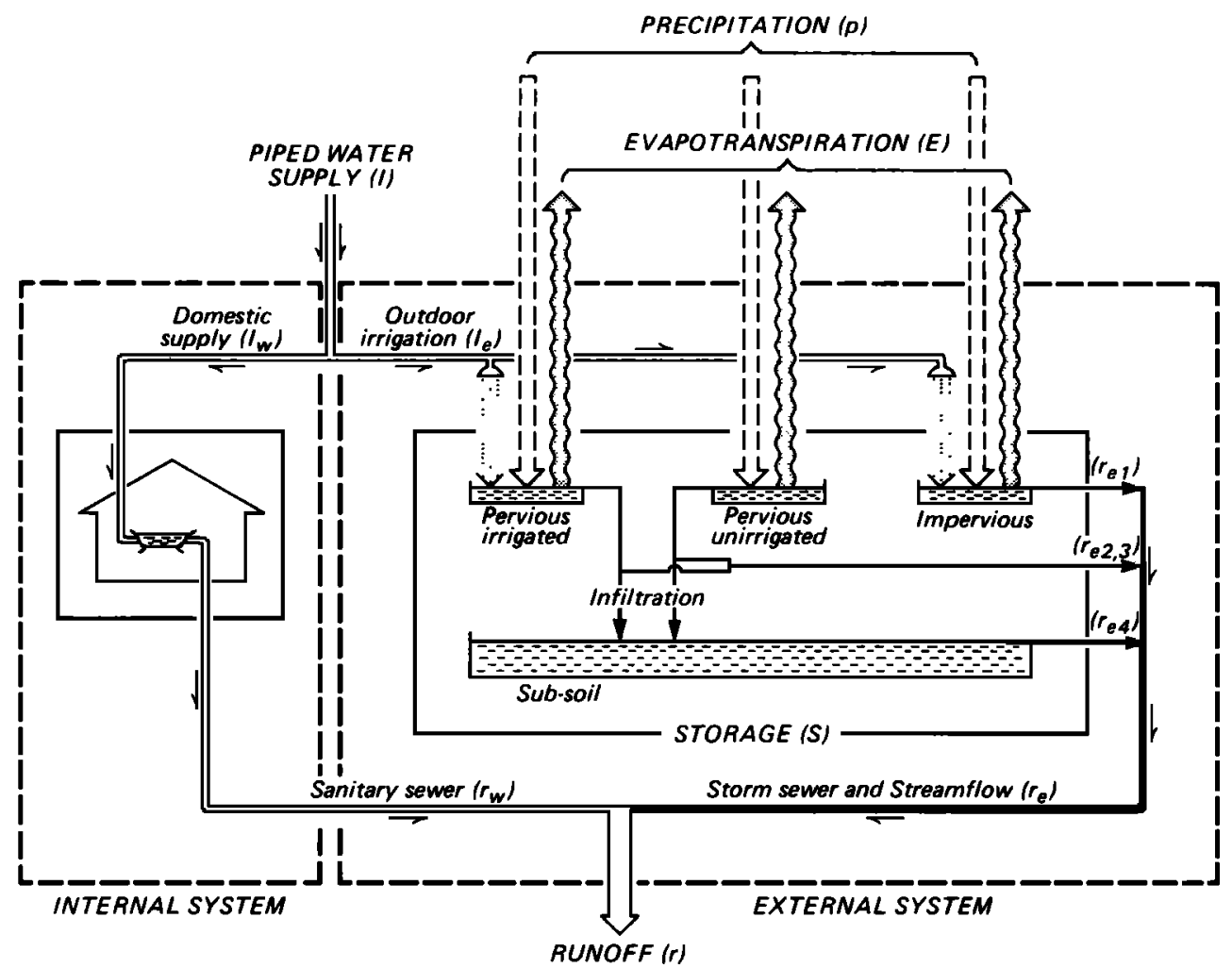

Fig. 1. The urban hydrologic system (internal and external components).

the internal portion of $r$ (which can be considered to be the base load of sewerage), is equivalent to [AWWA-CWU, 1973] the first of the above decoupling methods.

The modification of the hydrologic cycle which forms the external water system is usually viewed in a comparative (urban versus rural) framework. Urban precipitation modification is a controversial subject, but most climatologists agree that some degree of enhancement is to be expected, especially in the downwind suburban or rural area [Changnon, 1981]. In temperate regions, evapotranspiration and water storage are generally thought to be reduced by urbanization due to the partial waterproofing of the surface [Oke, 1982]; however, there is little work on the subject, and contradictions have been noted [Oke and McCaughey, 1983].
Water storage comprises two components: surface retention and soil storage. Surface retention includes both depression storage (surface puddles) and interception storage (held by surface cover such as vegetation and buildings) [Aron, 1982], while soil storage results from infiltration. When the ability of the soil to transport the infiltrated water is greater than the precipitation rate it can be assumed that all water falling on pervious areas enters soil storage after the surface retention is full.

A difficult problem in urban hydrology is the definition of appropriate catchment areas. Such definition can be based upon topography, the water supply pipe network, or the water removal pipe network. The latter can be complicated depending on the presence of combined sewers or separate sanitary

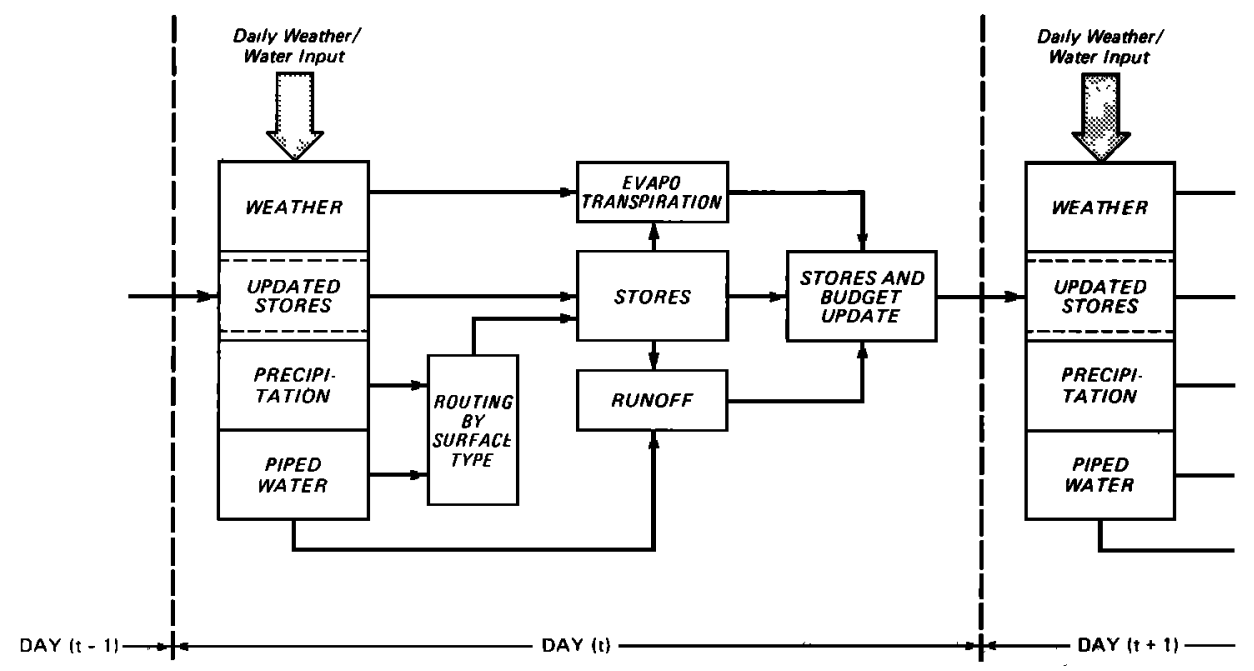

Fig. 2. Schematic depiction of the computational format of the water balance model for a day. 
and stormwater pipes. Very rarely do the three criteria coincide. It is important to investigate the extent to which net gain or loss of water occurs. Ideally, for water balance calculations an area with no net accumulation/depletion is required.

The nature of the surface cover is of fundamental importance in hydrologic study. A scheme to classify land cover of urban areas for climatologic purposes has been suggested by Auer [1978], but in the present model it is sufficient to recognize three simple surface types: impervious, irrigated pervious, and unirrigated pervious.

\section{MODEL}

The model presented here is designed to calculate the water balance components for an urbanized catchment. The time scale can be varied from 1 day to at least 1 year depending on the availability of appropriate input data. In the case outlined here it is suitable for daily calculations in a suburban area. This is determined by the form of the evapotranspiration submodel chosen.

The following description of the model is organized according to the order of calculation shown in the flow chart in Figure 2.

\section{Model Input}

The input necessary to specify the characteristics of the catchment is listed in Table 1 (top). It consists of information regarding the nature of the physical land cover, hydrologic properties of the surface and subsurface materials, data on water use, and the status of the various water storages at the time the model is to be initiated. This information is utilized in the partitioning by surface type, evapotranspiration, storage and runoff steps of the calculations (Figure 2).

Table 1 (bottom) gives the climatological and piped water inputs to the model. A new set of these data are required for every day of the model run. The precipitation and piped water specify the daily increment to the water balance; the remaining data are required by the evapotranspiration submodel. Guidance in estimating some of the less easily available inputs in Table 1 is offered in the final section of this paper.

\section{Areal Partitioning of Water Input}

An important concept in the model is the recognition that a suburban area can be subdivided into the three discrete surface types of hydroclimatic purposes, namely, (1) impervious (roads, parking lots, buildings), in terms of water availability this is considered to be a dichotomous surface: it is either wet (saturated) or dry; (2) pervious, unirrigated (lawns, other greenspace, and open land not artificially watered), capable of having a moisture status anywhere from totally wet to totally dry on a continuous scale; and (3) pervious, irrigated (lawns, parks, golf courses watered by sprinkling), assumed to be always wet.

The water input to the system is divided according to the fraction of the total catchment area occupied by the ith surface area $\boldsymbol{A}_{i}$. Therefore the precipitation volume received by the $i$ th surface type $p_{i}$ is

$$
p_{i}=A_{i} p
$$

where $p$ is the average depth of precipitation across the catchment. On the other hand, the piped water supply $I$ is not received by all surfaces. Only the external part of the supply $I_{e}$ can be used for irrigation. This can be found following the $A W W A-C W U[1973]$ relation, noted earlier, to be
TABLE 1. Catchment Parameters and Daily Data Requirements

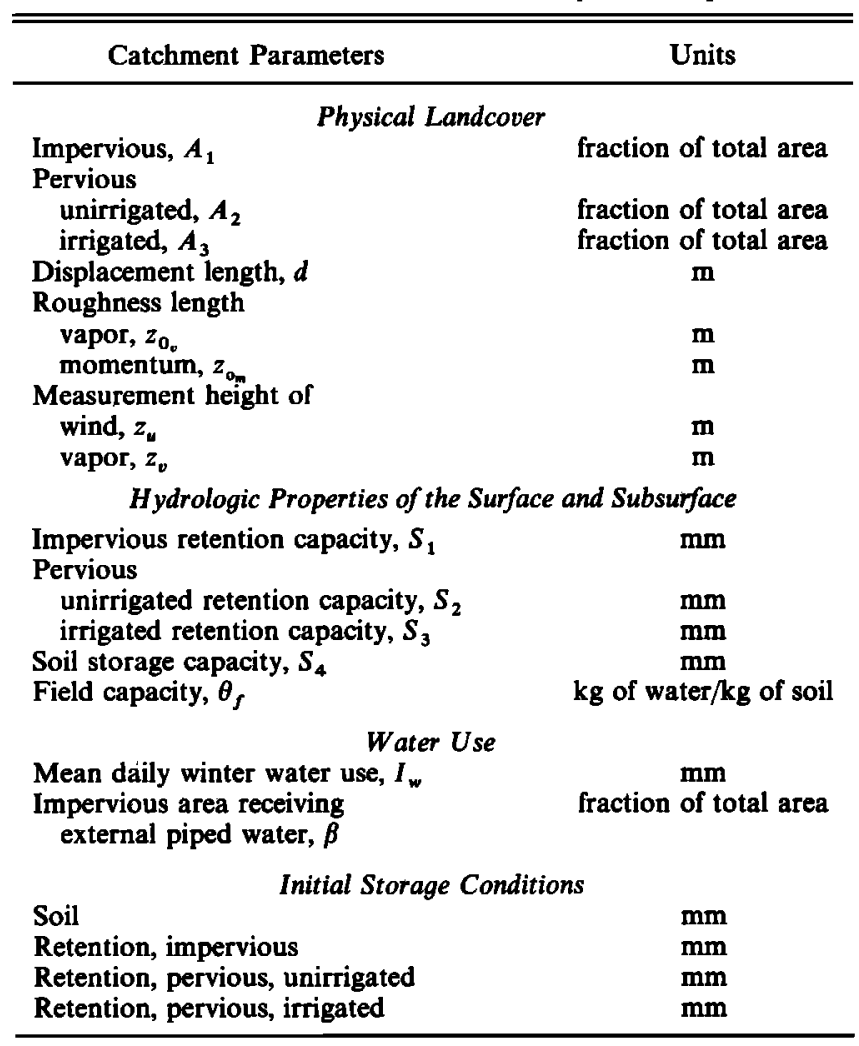

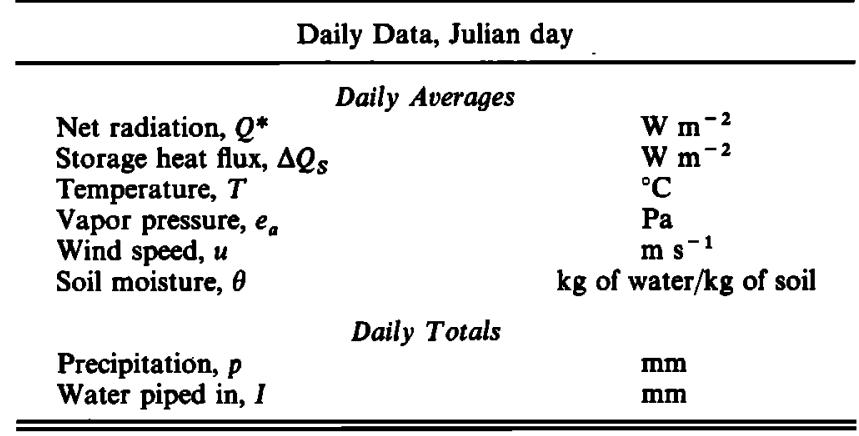

$$
I_{e}=I-I_{w}
$$

where $I_{w}$ is the mean daily winter water use. Furthermore, only pervious irrigated, or possibly impervious, surfaces are open to irrigation. The fraction of the impervious area being sprinkled $\beta$ is specified Table 1 (top).

\section{Stores and Runoff}

The retention characteristics of each surface type and the existing water content of each store (the three surface stores impervious $S_{1}$, irrigated pervious $S_{2}$, and unirrigated pervious $S_{3}$ and the soil store $S_{4}$ ) are taken into account in the calculation of runoff (Figure 2). When the retention capacity of a particular surface is exceeded a "cascade" is initiated leading to runoff as follows.

Impervious. At time $t$ if the combination of precipitation, irrigation and the water stored from the previous day $(t-1)$ exceeds the retention capacity of the store $S_{1}{ }^{c}$, then the excess runs off, i.e.,

if

$$
\left(p_{1}+I_{e 1}+S_{1}^{t-1}\right)>S_{1}{ }^{\mathrm{c}}
$$


then

$$
\begin{gathered}
r_{e 1}=\left(p_{1}+I_{e 1}+S_{1}{ }^{1-1}\right)-S_{1}{ }^{c} \\
S_{1}{ }^{t}=S_{1}{ }^{c}
\end{gathered}
$$

Pervious unirrigated. No irrigation input is received on these surfaces. If the infiltration rate $f_{2}$ exceeds the precipitation rate all water in excess of the retention capacity $S_{2}{ }^{c}$ goes to the soil store, i.e.,

if

$$
\begin{gathered}
\left(p_{2}+S_{2}{ }^{t-1}\right)>S_{2}{ }^{c} \\
p_{2}<f_{2}
\end{gathered}
$$

then

$$
S_{4}{ }^{t}=\left(p_{2}+S_{2}{ }^{t-1}\right)-S_{2}{ }^{c}
$$

On the other hand, if

$$
p_{2}>f_{2}
$$

then

$$
\begin{gathered}
S_{4}{ }^{t}=\left(f_{2}+S_{2}{ }^{t-1}\right)-S_{2}{ }^{c} \\
r_{e 2}=p_{2}-f_{2}-S_{2}{ }^{c}
\end{gathered}
$$

and for both cases $S_{2}{ }^{t}=S_{2}{ }^{c}$. The infiltration can be computed using an equation such as the Horton infiltration equation [see Aron, 1982].

Pervious irrigated. In this case the equations are the same as above except for the inclusion of the irrigation term $I_{e 3}$.

Soil. If the infiltration fills the soil storage capacity, soil runoff is generated, i.e.,

if

$$
S_{4}{ }^{\prime}>S_{4}{ }^{c}
$$

then

$$
r_{e 4}=S_{4}{ }^{t}-S_{4}{ }^{c}
$$

The model considers five sources of runoff (Figure 1). The first is from impervious surfaces, $r_{e 1}$, the second is from pervious unirrigated surfaces when the preciptation rate exceeds the infiltration rate, $r_{e 2}$, the third is the equivalent from pervious irrigated areas, $r_{e 3}$, the fourth is from saturated pervious areas, $r_{e 4}$, and the fifth is the sanitary sewer flow from the internal piped water supply, $r_{w}$. So $r=r_{e}+r_{w}$, where $r_{e}=r_{e 1}+r_{e 2}$ $+r_{e 3}+r_{e 4}$, and $r_{w}=I_{W}$ (following $A W W A-C W U$ [1973] and equation (3)).

\section{Evapotranspiration}

Since there were no existing models to calculate evapotranspiration from urban areas, it was necessary to develop one. That forwarded here is a version of the well-known combination model (incorporating terms to account for the roles of energy availability and aerodynamic influences on evapotranspiration) with modifications to allow for special suburban characteristics. These special features include recognition of the wide diversity of surface types encountered (i.e., the three already noted) and the possibility of "oasis"-type advection. No special provision is made for vaporization due to fuel combustion or the physiological control exerted by plants.

Evapotranspiration calculations in the submodel depend on the general state of surface wetness as follows.

1. Wet: when surface retention storage is nonzero, and/or on days receiving more than $5 \mathrm{~mm}$ of rainfall. (The threshold rainfall value is not critical to the operation of the model. The suggested figure is based on field experience.) On these occasions all three surface types are assumed to be wet and to lose water to the air at the potential rate given by Priestley and Taylor [1972]:

$$
E=\left(\alpha / L_{v}\right)[s /(s+\gamma)]\left(Q^{*}-\Delta Q_{s}\right)
$$

where $E$ is evapotranspiration, $L_{v}$ is the latent heat of vaporization, $s$ is the slope of the saturation vapor pressure versus temperature relationship, $\gamma$ is the psychrometric constant, $Q^{*}$ is the net all-wave radiation flux density, and $\Delta Q_{s}$ the subsurface heat flux density. This equation has been shown to apply over suburban terrain in wet conditions with the value of $\alpha$, an empirical coefficient, between 1.2 and 1.3 [Kalanda et al., 1980; Oke and McCaughey, 1983]. Here the value used is $\alpha=1.28$, which is in agreement with Brutsaert [1982].

2. Moist or "dry": when the impervious surfaces are dry; irrigated are wet; and the unirrigated are either moist or dry. Evapotranspiration is then calculated by the following modified version of Brutsaert and Stricker's [1979] advectionaridity equation:

$$
\begin{array}{r}
E=\left(1 / L_{v}\right)\left\{\left[(2 \alpha-1)(s /(s+\gamma))\left(Q^{*}-\Delta Q_{s}\right) \sum_{i=2}^{n} A_{i} \alpha_{i}^{\prime}\right]\right. \\
\left.-\left[A A(\gamma /(s+\gamma)) E_{a}\right]\right\}
\end{array}
$$

where $A_{i}$ is the proportion of the catchment covered with the $i$ th surface type, $\alpha_{i}{ }^{\prime}$ is the empirical coefficient of the $i$ th surface type, $A A$ is the status of the soil moisture related to area, and $E_{a}$ is the so-called drying power of the air:

$$
\begin{aligned}
E_{a}=(C / \gamma)\left(\bar{e}^{*}-\bar{e}_{a}\right)\left\{\left(\bar{u} / k^{2}\right) /[\right. & \left(\ln \left(z_{v}-d+z_{0 v} / z_{0 v}\right)\right) \\
\cdot & \left.\left.\left(\ln \left(z_{u}-d+z_{0 m}\right) / z_{0 m}\right)\right]\right\}
\end{aligned}
$$

where $C$ is the heat capacity of dry air, $\bar{e}^{*}$ and $\bar{e}_{a}$ are the mean saturation and ambient vapor pressures at height $z_{v}$, respectively, $u$ is the mean horizontal wind speed at height $z_{u}, k$ is the von Karman constant $(0.40), d$ is the zero-plane displacement length, and $z_{0_{v}}$ and $z_{0_{m}}$ are the water vapor and momentum roughness lengths respectively.

The suburban modifications incorporated in (5) are twofold. First, the juxtaposition of wet and dry suburban surfaces is known to increase $E$ due to oasis-type advection [Oke, 1979; Oke and McCaughey, 1983]. The inclusion of $\alpha_{i}^{\prime}$ weighted by the proportion of the total area covered by that surface type in the first term of (5) allows for this augmentation. Estimation of $\alpha_{2}{ }^{\prime}$ for the unirrigated surface area is based on the observed amount of soil moisture present in such surfaces and the equation of Davies and Allen [1973] (see the appendix). The irrigated areas are expected to exhibit the largest advective effects. The method used to estimate values of $\alpha_{3}{ }^{\prime}$ (appendix) accounts for the relative dryness of surrounding surfaces (using $\left.\alpha_{2}{ }^{\prime}\right)$ and the magnitude of available energy $\left(Q^{*}-\Delta Q_{s}\right.$ ). Using a 1980 Vancouver data set values of $\alpha_{3}{ }^{\prime}$ were assigned as shown in the appendix. Their resulting magnitude seems to be in correspondence with the results of Shuttleworth and Calder [1979] for forested surfaces.

The second modification is the addition of $A A$ into the second term of (5). This coefficient, calculated as in the appendix, is related to the areal moisture status of the suburb and recognizes the fact that the impact of the aerodynamic aridity term will be directly correlated with the proportion of the total area possessing available moisture. 
The evapotranspiration model was tested using data from the Sunset suburban site in Vancouver, British Columbia. Energy balance and climatological observations have been conducted from a $30-\mathrm{m}$ tower at this location during the summer and fall periods of 1977,1978 , and 1980 . The area consists of single family housing (64\% greenspace, $36 \%$ impervious, i.e., built). The evapotranspiration rates were determined using the Bowen ratio-energy balance and/or eddy correlation-energy balance approaches. The former used reversing psychrometers the latter a yaw sphere-thermometer system. Both required net radiation from a pyrradiometer and subsurface heat storage from a parameterization. Full details of the site and instrumentation are available in the works by Kalanda et al. [1980], Steyn [1980], and Oke and McCaughey [1983].

A plot of the evapotranspiration estimates (using the model outlined here and climatological input from the Sunset site) versus the measured values (using the Sunset tower energy balance data) is given in Figure 3. The data include both the 1980 results used to assign the model coefficients and completely independent data from 1977 and 1978. The individual year and aggregate statistics are shown in Table 2 . For most hydrologic purposes, mean bias and root mean square errors of about $0.5 \mathrm{~mm}$ are probably satisfactory for daily evapotranspiration estimates. It may also be noticed that the scatter becomes largest at intermediate values. This may indicate that the threshold for advective effects is improperly parameterized, or is not amenable to simple analysis.

\section{Stores and Budget Update}

After accounting for water loss due to runoff and evapotranspiration, the status of the retention and soil stores is updated (Figure 2). The partitioning of evaporative losses is based on the areal fractions occupied by each surface and which of the two evapotranspiration equations was used. If the "wet" equation (4) was used, all three surfaces are involved. The case of the impervious surface adds a slight com-

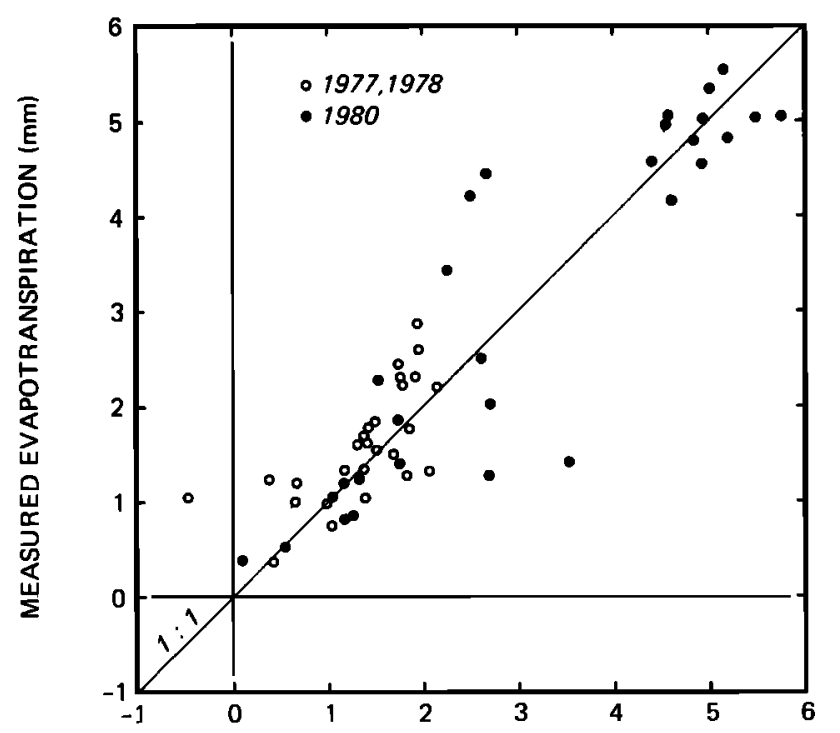

MODELLED EVAPOTRANSPIRATION $(\mathrm{mm})$

Fig. 3. Relationship between modeled and measured daily evapotranspiration. Measured values are from the Vancouver Sunset site. Solid circles are the data used to develop the model coefficients, open circles are independent test data.
TABLE 2. Comparison of Measured and Modeled Evapotranspiration

\begin{tabular}{lcccc}
\hline Year & $n$ & $r^{2}$ & $\begin{array}{c}\text { Mean } \\
\text { Bias } \\
\text { Error, } \\
\text { mm }\end{array}$ & $\begin{array}{c}\text { Root Mean } \\
\text { Square } \\
\text { Error, } \\
\text { mm }\end{array}$ \\
\hline 1980 & 29 & 0.81 & 0.54 & 0.77 \\
1977,1978 & 27 & 0.47 & 0.43 & 0.56 \\
\hline
\end{tabular}

Field data are daily average values for the Sunset suburban site in Vancouver, British Columbia; n, number of days for which data are available.

plication. Evaporative losses from the impervious and pervious areas are

$$
E_{1}=E \cdot A_{1} \quad E_{2+3}=E-E_{1}
$$

respectively. Therefore the updated impervious retention storage for the next day $(t+1)$ is

$$
S_{1}{ }^{+1}=S_{1}{ }^{t}-E_{1}
$$

To avoid computing negative storage values when $E>S$, a surplus loss adjuster $M=\left|S_{1}{ }^{t+1}\right|$ is introduced so that $S_{1}{ }^{t+1}=0$. Then $E_{2+3}$ is supplemented by $M$.

If the "moist-dry" equation (5) is used to calculate $E$, only pervious surfaces are involved in the update, none of the preceding adjustment is necessary, and $E_{2+3}=E$.

Following this partitioning of $E$, irrespective of the equation used, the calculations continue as follows:

$$
S_{2}{ }^{+1}=S_{2}{ }^{t}-\left(E_{2+3}\left[A_{2} /\left(A_{2}+A_{3}\right)\right]\right)
$$

and if

$$
\begin{aligned}
& S_{2}{ }^{\mathrm{t}+1}<0 \quad M=\left|S_{2}{ }^{\mathrm{t}+1}\right| \quad S_{2}{ }^{t+1}=0 \\
& S_{3}{ }^{\mathrm{t}+1}=S_{3}{ }^{t}-\left(E_{2+3}\left[A_{3} /\left(A_{2}+A_{3}\right)\right]+M\right)
\end{aligned}
$$

and if

$$
\begin{aligned}
S_{3}{ }^{t+1}<0 \quad M & =\left|S_{3}{ }^{t+1}\right| \quad S_{3}{ }^{t+1}=0 \\
S_{4}{ }^{t+1} & =S_{4}{ }^{t}-M
\end{aligned}
$$

Following this update the new daily water balance can be calculated (Figure 2). The results can be aggregated to give monthly, seasonal and annual balances and derived parameters such as the runoff and evapotranspiration ratios. The balances can refer to the whole hydrologic system (internal plus external) or to the external system alone.

\section{SENSITIVITY ANALYSES}

The model presented in the preceding sections consists of a scheme for partitioning water within an urban hydrologic system and a submodel for estimating evapotranspiration from such a system. While the partitioning scheme is a relatively simple one, and the evapotranspiration model is a modification of existing ones, an examination of the sensitivity of computed results to input parameters remains a useful exercise. An examination of the partitioning scheme and evapotranspiration equations reveals that with two minor exceptions, the model is a strictly linear one. The two exceptions are the nonlinear dependence of evapotranspiration on $z_{0_{v}}$ and $z_{0_{m}}$. The linearity permits the model sensitivity to be expressed as a (constant) slope. 


\section{Evapotranspiration}

While the Priestley-Taylor equation (equation (4)) has wellknown dependence on net radiation, storage heat flux, and temperature, the behavior of (5) is somewhat more complicated, as is shown in Table 3 . In addition to these dependencies, the evapotranspiration is weakly dependent on $\theta / \theta_{f}$ (the relative soil moisture) via $A A$. Step changes in $A A$ (and hence evapotranspiration) occur as $\theta / \theta_{f}$ varies about the two critical values of 0.6 and 0.3 (see Table 2). Within the water balance model the evapotranspiration submodel influences both soil storage and runoff. The linkages cannot be expressed without reference (case specific) to antecedent conditions. However, they will be more evident in transition periods (spring and fall).

\section{Water Inputs and Catchment Parameters}

The formal notion of model sensitivity is not clearly applicable to these parameters. The nature of the model is such that some of the internal variables act like switches whose state depends on critical values of the variables and often antecedent conditions. A good example of this is the dependence of runoff on soil storage. When soil storage is below capacity, runoff occurs only from impervious areas, whereas under conditions of full storage capacity, runoff occurs from the entire area. A change in water input or size of storage capacity will thus alter the day on which runoff generation switches state (i.e., from impervious surfaces only to all surfaces, or vice versa).

\section{IMPLEMENTATION OF THE MODEL}

Most of the input data necessary to run the model (Table 1) are easily obtained. They include the simple catchment descriptors such as the proportions of pervious and impervious cover and values of surface retention storage, soil storage, and field capacity which can be assessed from tables (see, for example, Brater [1968]). The standard daily climatological input is usually readily available, although urban station networks may be sparse. If only nonurban stations are available some allowance must be made for urban effects on climate [Page, 1972].

Some terms present greater difficulty. Water pipe data are available in cities where use is metered, but the information may be in a highly aggregated form. If meter data are not available, recourse must be made to statistical relationships relating water use to daily climatological data (see, for example, Grimmond [1983], Maidment et al. [1985], and S. M. Loudon and T. R. Oke, unpublished manuscript, 1986). Such algorithms are site specific and should be transferred to other sites with caution. The value of the mean winter water use (used to estimate internal domestic use and sanitary sewage) should be available from the city water engineer, and the areal coverage of sprinkling on pervious cover can be gauged from simple field surveys, since the model output is not overly sensitive to this parameter. Note that if sprinkling occurs in winter the mean summer water use should be used.

Net radiation and the subsurface heat flux data are not routinely gathered. Net radiation can be obtained by linear regression analysis using solar, or net solar, radiation as the predictor [Davies and Idso, 1979]. Sunshine hours or cloud cover have also been used [Revfeim, 1981]. Net solar radiation requires knowledge of the suburban surface albedo; values for
TABLE 3. Sensitivity Analysis of the Evapotranspiration Model (Equation (5))

\begin{tabular}{cc}
\hline Input & Average Slope \\
\hline & Climatological Parameters \\
$Q$ & $0.04 \mathrm{~mm} \mathrm{~W}^{-1} \mathrm{~m}^{-2}$ \\
$\Delta Q_{s}$ & $-0.04 \mathrm{~mm} \mathrm{~W} \mathrm{~m}^{-2}$ \\
$T$ & $0.08 \mathrm{~mm} / \mathrm{C}^{\circ}$ \\
$e_{a}$ & $0.002 \mathrm{~mm} / \mathrm{Pa}^{-1}$ \\
$\bar{u}$ & $-1.47 \mathrm{~mm} \mathrm{~m} \mathrm{~s}^{-1}$ \\
& Catchment Parameters \\
$A_{3}$ & $0.02 \mathrm{~mm} / \%$ \\
$d$ & $-0.25 \mathrm{~mm} / \mathrm{m}^{*}$ \\
$z_{0_{v}}$ & $-7.14 \mathrm{~mm} / \mathrm{m}^{*}$ \\
$z_{0_{m}}$ & $-0.91 \mathrm{~mm} / \mathrm{m}^{*}$ \\
\hline
\end{tabular}

$Q$ and $T$ affect $L_{v}, s, \gamma$, and $\bar{e}^{*}$.

*Slightly nonlinear.

urban and suburban areas are given in the work by Oke [1986]. Alternatively, net radiation can be calculated as the sum of the net solar and net longwave radiation. The latter can be found using one of an array of empirical relations requiring only standard air temperature, or temperature and humidity, observations (see, for example, Davies and Idso [1979] and Brutsaert [1982]). Once the net radiation is known the storage heat flux can be parameterized using a scheme such as that of Oke et al. [1981]. The only additional information needed for this relation are the fractions of the surface covered by impervious and pervious land uses.

Estimation of surface aerodynamic characteristics for cities is not straightforward. Values of the zero-plane displacement and roughness lengths may be obtained from wind profile measurements, algorithms based on measures of surface roughness geometry, or inspection of tables, in reverse order of ease. For most hydrologic studies the first approach is too detailed and expensive, the second is time consuming but possible and site sensitive, and the third is a practical last resort. Equations for calculating these parameters from geometric information can be found in the work Kutzbach [1961], Lettau [1969], Oke [1974], and Brutsaert [1982]. Tables of urban and suburban values are given by Engineering Science Data Unit [1972], Oke [1974], and Counihan [1975]. The water vapor roughness length can be approximated using the relationship between transfer coefficients and the momentum roughness length given by Brutsaert [1982].

Grimmond and Oke [1986] show the full model to perform in a realistic manner in the case of a suburb of Vancouver, British Columbia, although a full set of independent data were not available to validate the model. Vancouver experiences a temperate climate with frequent frontal rainfall in winter and mild drought in summer. Many other mid-latitudes cities have broadly similar conditions where the model may be appropriate. Vancouver may be atypical because of its large amounts of greenspace areas and irrigation, but the model incorporates these as variables. On the other hand, cities experiencing extended periods with snow cover, or frozen ground, present special hydrologic characteristics that are not built into the model. In terms of applicability, the most restrictive part of the scheme is likely to be the evapotranspiration submodel. It incorporates empirical coefficients derived from Vancouver observations which limit its transferability. Other urban evapotranspiration observations of sufficient quality to test the submodel are unfortunately almost nonexistent at present. 
APPENDIX: DETERMINATION OF COEFFICIENTS $\alpha_{i}^{\prime}$ AND $A A$ IN EQUATION (5)

1. Calculation of $\alpha_{2}^{\prime}$ [Davies and Allen, 1973]:

$$
\alpha_{2}^{\prime}=\alpha\left[1-\exp \left(-b \theta / \theta_{f}\right)\right]
$$

where $\alpha=1.28, b=10.563, \theta$ is soil moisture in the upper 0.2 $\mathrm{m}$ layer, and $\theta_{f}$ is soil moisture at field capacity.

2. Calculation of $\alpha_{3}{ }^{\prime}$ (from 1980 data):

if

$$
\alpha_{2}{ }^{\prime}<1.0
$$

then

$$
\alpha_{3}{ }^{\prime}=\alpha=1.28
$$

if

$$
\alpha_{2}^{\prime}>1.0
$$$$
\left(Q^{*}-\Delta Q_{S}\right)=8.64 \text { to } 10.37 \mathrm{MJ} \mathrm{m}^{-2} \mathrm{~d}^{-1} \quad \alpha_{3}^{\prime}=1.70
$$

if

$$
\left(Q^{*}-\Delta Q_{s}\right)>10.37 \mathrm{MJ} \mathrm{m}^{-2} \mathrm{~d}^{-1} \quad \alpha_{3}{ }^{\prime}=2.60
$$

3. Calculation of $\boldsymbol{A A}$

if

$$
\theta / \theta_{f}>0.6 \quad A A=A_{2}+A_{3}
$$

if

$$
0.3<\theta / \theta_{f}<0.6 \quad A A=\left(A_{2}+2 A_{3} / 2\right)
$$

if

$$
\theta / \theta_{f}<0.3 \quad A A=A_{3}
$$

where $A_{2}$ and $A_{3}$ are the fractions of the suburban area with pervious surfaces that are unirrigated and irrigated, respectively.

Acknowledgments. This work was supported by funds from the Natural Sciences and Engineering Research Council of Canada. The constructive comments of $\mathbf{M}$. Church were much appreciated as was the help provided by B. Kalanda and S. Loudon in gathering data for Figure 3. The diagrams were drawn by $P$. Jance.

\section{REFERENCES}

Alley, W. M., D. R. Dawdy, and J. C. Schaake, Jr., Parametricdeterministic urban watershed model, J. Hydraulics Div. Am. Soc. Civ. Eng., 106(HY5), 679-690, 1980.

American Water Works Association, Committee on Water Use, Trends in water use, J. Am. Water Works Assoc., 65, 285-300, 1973.

Aron, G., Rainfall abstractions, in Urban Stormwater Hydrology, edited by D. F. Kibler, Water Resour. Monogr. 7, pp. 69-86, AGU, Washington, D. C., 1982

Auer, A. H., Jr., Correlation of land use with meteorological anomalies, J. Appl. Meteorol., 17, 636-643, 1978.

Brater, E. F., Steps toward a better understanding of urban runoff processes, Water Resour. Res., 4, 335-347, 1968.

Brutsaert, W., Evaporation in to the Atmosphere: Theory, History and Applications, 299 pp., D. Reidel, Hingham, Mass., 1982.

Brutsaert, W., and H. Stricker, An advection-aridity approach to estimate actual regional evapotranspiration, Water Resour. Res., 15, 443-450, 1979.

Changnon, S. A., Jr., METROMEX: A review and summary, Meteorol. Monogr., 18(40), 181 pp., 1981.

Counihan, J., Adiabatic atmospheric boundary layers: A review and analysis of data from the period 1880-1972, Atmos. Environ., 9 871-905, 1975

Davies, J. A., and C. D. Allen, Equilibrium, potential, and actual evaporation from cropped surfaces in southern Ontario, $J$. Appl. Meteorol., 12, 649-657, 1973.

Davies, J. A., and S. B. Idso, Estimating the surface radiation balance and its components, in Modification of the Aerial Environment of Plants, edited by B. J. Barfield, and J. F. Gerber, pp. 183-210, American Society of Agricultural Engineers, St. Joseph, Mich., 1979.

Engineering Science Data Unit, Characteristics of wind speed in the lower layers of the atmosphere near the ground: Strong winds (neutral atmosphere), Eng. Sci. Data Item 72026, Eng. Sci. Data Unit, London, 1972.

Grimmond, C. S. B., The suburban water balance: daily, monthly and annual results from Vancouver, M.Sc. thesis, 172 pp., Dep. of Geogr., Univ. of B. C., Vancouver, 1983.

Grimmond, C. S. B., and T. R. Oke, Urban water balance, 2, Results from a suburb of Vancouver, British Columbia, Water Resour. Res., this issue.

Hengeveld, H., and C. De Vocht, Role of water in urban ecology, Urban Ecol., 6, 362 pp., 1982.

Kalanda, B. D., T. R. Oke, and D. L. Spittlehouse, Suburban energy balance estimates for Vancouver, B. C., using the Bowen ratioenergy balance approach, J. Appl. Meteorol., 19, 791-802, 1980.

Kutzbach, J. E., Investigations of the modification of wind profiles from artifically controlled surface roughness, Annual Report, Dep. of Meteorol., Univ. of Wisc., Madison, 1961.

Lettau, H. H., Note on aerodynamic roughness-parameter estimation on the basis of roughness-element description, J. Appl. Meteorol., 8, 828-832, 1969.

Maidment, D. R., S. P. Miaou, D. N. Nvule, and S. G. Buchberger, Analysis of daily water use in nine cities, $C R W R 201,67 \mathrm{pp}$., Cent. for Res. in Water Resour., The Univ. of Tex. at Austin, 1985.

Oke, T. R., Boundary Layer Climates, 372 pp., Methuen, London, 1978.

Oke, T. R., Review of urban climatology 1973-1976, WMO Tech. Note 169, World Meteorol. Org., Geneva, 1979.

Oke, T. R., The energetic basis of the urban heat island, $Q . J . R$. Meteorol. Soc., 108, 1-24, 1982.

Oke, T. R., The surface energy budgets of urban areas, Meteorol. Monogr., in press, 1986.

Oke, T. R., and J. H. McCaughey, Suburban-rural energy balance comparisons for Vancouver B.C.: An extreme case? Boundary Layer Meteorol., 26, 337-354, 1983.

Oke, T. R., B. D. Kalanda, and D. G. Steyn, Parameterisation of heat storage in urban areas, Urban Ecol., 5, 45-54, 1981.

Page, J. K., The problem of forecasting the properties of the built environment from the climatological properties of the green-field site, in Weather Forecasting for Agriculture and Industry, edited by J. A. Taylor, pp. 195-208, David and Charles, Newton Abbot, 1972.

Priestley, C. H. B., and R. J. Taylor, On the assessment of surface heat flux and evaporation using large-scale parameters, Month. Weather Rev., 100, 81-92, 1972.

Revfeim, K. J. A., Estimating solar radiation income from "bright" sunshine records, Q. J. R. Meteorol. Soc., 107, 427-435, 1981.

Shuttleworth, W. J., and I. R. Calder, Has the Priestley-Taylor equation any relevance to forest evaporation? J. Appl. Meteorol., 18, 639-646, 1979.

Steyn, D. G., Turbulent diffusion and the daytime mixed layer depth over a coastal city, Ph.D. Thesis, 161 pp., Dep. of Geogr., Univ. of B C., Vancouver, 1980.

Wenzel, H. G., Jr., and M. L. Voorhees, Adaptation of ILLUDAS for continuous simulation, J. Hydraul. Div. Am. Soc. Civ. Eng., 106(HY11), 1795-1812, 1980.

C. S. B. Grimmond, T. R. Oke, and D. G. Steyn, Department of Geography, The University of British Columbia, Vancouver, British Columbia, V6T 1W5, Canada.

(Received October 3, 1985; revised April 11, 1986; accepted May 5, 1986.) 